\title{
Whole-Body Vibration, Morphological and Antioxidant Effects on the Diaphragm Muscle of Obese Rats
}

\author{
M. de Campos Oliveira, M. Laís Boaretto, A. Barbosa, A. T. Bittencourt Guimarães, \\ G. R. Flor Bertolini, M. M. Torrejais, R. M. Costa
}

Postgraduate Program in Biosciences and Health, State University of Western Paraná (UNIOESTE), Cascavel, Paraná, Brazil

\section{CORRESPONDING AUTHOR: \\ Gladson Ricardo Flor Bertolini \\ State University of Western Paraná \\ Cascavel Campus \\ Universitária St 2069 \\ 85819-110 Cascavel (PR), Brazil \\ E-mail: gladsonricardo@gmail.com}

\section{DOI:}

10.32098/mltj.04.2021.06

LEVEL OF EVIDENCE: 1B

\begin{abstract}
SUMMARY
Background. This study aimed investigating the effects of whole-body vibration (WBV) on morphological parameters and the antioxidant system of the diaphragm muscle of Wistar rats with monosodium glutamate (MSG) obesity induction.

Methods. 28 animals were separated into two groups: obesity (administration of MSG) and control group. At 80 days of age, the groups were subdivided and training with WBV was started for eight weeks, constituting the control (GC), WBV control (GCP), obese (GO) and obese WBV (GOP) groups. At the end of the experimental period, when the animals were 136 days old, euthanasia and removal of the diaphragm muscle occurred. The right muscle anthem was prepared for histological analysis, quantification of total proteins and oxidative stress.

Results. Obese animals exhibited a reduction in the cross-section area of fiber types IIA, IIB, and total proteins; as for the enzymes of oxidative stress, there was a reduction in catalase activity and an increase in glutathione S-transferase. On the other hand, in the animals trained, there was a reduction in the amount of fiber type IIB, inferring possible deleterious effects on the contractile capacity of strength and an increase in the activity of the glutathione S-transferase enzyme, which was also verified in the group of association of obesity and training, besides a reduction in the activity of glutathione reductase.

Conclusions. Obesity caused a reduction in the total proteins of the diaphragm muscle, as well as a decrease in the area of type IIA and IIB fibers and enzymes in the antioxidant defense system. The WBV has not been able to reverse the effects caused by obesity.
\end{abstract}

\section{KEY WORDS}

Oxidative stress; exercise; bypothalamic obesity; muscle tissue; diaphragm.

\section{INTRODUCTION}

The excessive or abnormal accumulation of fat from obesity has been associated with numerous comorbidities and medical complications and is considered an important public health problem (1). Among the damages to health, cardiovascular diseases, type 2 diabetes, and several types of cancers stand out (2). Thus, it is verified that obesity compromises the health and daily activities of the individual, which makes weight loss a necessity in the recovery of quality of life (3).

The regular practice of physical exercises has been pointed out as a positive factor associated with health, contributing to the prevention and control of diseases such as obesity and its comorbidities (4). The planned, structured and repetitive physical activity, which characterizes physical exercise, brings numerous benefits to health, such as improved physical conditioning, decreased loss of bone and muscle mass, improved cardiorespiratory fitness and increased strength, coordination and balance (4-7).

There is a diversity of types and modalities of exercises, including activities in which equipment is used, such as those that produce vibration (8), which can be local, in a specific limb, or whole-body (WBV) and generate muscle strength gains (9-11). The WBV causes alterations in the musculoten- 
dinous length, by transmitting mechanical stimuli to receptors, leading to stimulation of the muscle spindles, which results in reflex neural activity with consequent muscle contraction (12). This physiological mechanism promotes an increase in energy expenditure and, consequently, an increase in calorie burning. When used in strength training, the vibrations show an increase in these parameters, which provides an improvement in physical performance, physical rehabilitation, and an increase in muscle mass (7, 13). Furthermore, according to Zago et al. (14) WBV is a promising form of intervention for obese women and can improve cardiac autonomic function, reduce peripheral and central arterial stiffness, increase insulin sensitivity and glucose regulation, improve muscle strength, and reduce body weight. Alavinia et al. (15) also in a meta-analysis points to a reduction in body weight and fat mass, especially when WBV is associated with other measures such as diet and exercise.

In an obese condition, the muscle system is compromised because the inspiratory muscles - especially the diaphragm - receive deep influence and work overload, which can lead to a reduction in respiratory strength (16). Thus, the training of this musculature aiming at improving resistance is of utmost importance, and exercise with WBV can become advantageous due to the effects on the improvement ventilation and its systemic action $(13,17)$.

Few studies investigate the influences of physical exercise on the morphological structure of the inspiratory diaphragmatic muscle, which is considered the most important in the act of breathing. Reid et al. (18) analyzed in hamsters the morphology of the diaphragm using swimming exercise; however, no significant differences were observed in the cross-sectional area of muscle fibers and also in the percentage of fiber types, showing that its effect on the diaphragm seems to be less than other interventions, such as running on a treadmill or the inspiratory resistance load. Luciano and Mello (19) verified in diabetic rat diaphragms a reduction in total protein levels, with the improvement in this parameter after swimming exercise. Even if swimming, also considered an aerobic exercise involving the limbs, as occurs with WBV, has presented relevant data, these are still controversial (20). In this context, the effects of WBV on morphological parameters and the antioxidant system of the diaphragm muscle were investigated in an experimental model of monosodium glutamate (MSG) obesity induction.

\section{METHODS}

A total of 28 male Wistar rats were kept under controlled light conditions (light/dark cycle $12 \mathrm{~h}$ ) and temperature (23 $\left.\pm 2{ }^{\circ} \mathrm{C}\right)$, in standard cages $(41 \mathrm{~cm}$ long $\times 34 \mathrm{~cm}$ wide $\times 17 \mathrm{~cm}$ high), with access to standard rodent feed (BioBase, Santa Catarina, SC, Brazil) and ad libitum water.

All experiments were conducted following national and international legislation (21) and with the approval of the Ethics Committee on the Use of Animals at the Universidade Estadual do Oeste do Paraná (Unioeste): experimental certificate on the use of animals in research number 08/18 - CEUA.

\section{Experimental groups}

The animals were initially separated into two groups: control (GC, $\mathrm{n}=14)$ and obese (GO, $\mathrm{n}=14)$. During the first five days of life, GO animals received injections of MSG at a dose of $4 \mathrm{mg} / \mathrm{g}$ body weight and, to go through the same stress, GC received a subcutaneous saline solution at a dose of $1.25 \mathrm{mg} / \mathrm{g}$ body weight (22). The day of birth was considered day zero and the injections started on day one (figure 1).

At 70 days of age, the training with WBV was initiated, causing both groups to be subdivided into two more: the control group submitted to the vibration platform (GCP, $\mathrm{n}$ $=7)$ and the obese group submitted to the vibration platform $(\mathrm{GOP}, \mathrm{n}=7)$.

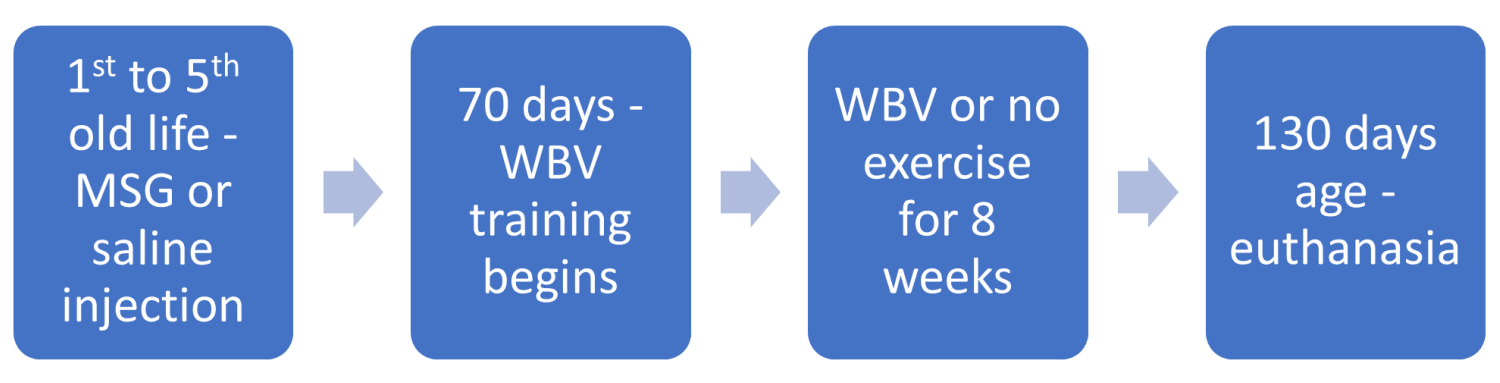

Figure 1. Time scheme for performing different steps of the experiment with the live animal. 


\section{WBV Protocol}

The commercial Vibro-oscillatory platform (Arktus, Brazil) was used three times a week for 10 minutes for eight consecutive weeks, with at least 48 hours of rest between sessions. The exercise protocol was adapted to a $60 \mathrm{~Hz}$ frequency with an amplitude of two millimeters (23).

The animals were positioned and contained in an MDF wooden support, with compartments $13 \mathrm{~cm}$ wide, $19 \mathrm{~cm}$ long and $25 \mathrm{~cm}$ high. In each training, the animals were rotated in the enclosures to minimize biases resulting from the difference in vibration amplitude in the different areas of the platform.

\section{Collection of the diaphragm muscle}

At 130 days of age, after finishing the training with the vibration platform, the animals were desensitized in a $\mathrm{CO}_{2}$ chamber and eutanasiated with the aid of the guillotine. The animals were kept in a ventral position and an incision in the median region was made just below the thorax, with the skin and muscles subsequently folded. The removal of the diaphragm consisted only of its costal part, being divided into right and left anterms.

\section{Histoenzimological analysis}

A sample of the right antler of the diaphragm muscle was kept at room temperature for a period of 30 to 40 minutes. After this time, the sample was covered with neutral talc and frozen in liquid nitrogen for subsequent storage in Biofreezer at $-80{ }^{\circ} \mathrm{C}$. During processing, the frozen muscle samples were transferred to a cryostat chamber (LUPETEC CM 2850 Cryostat Microtome) at $-30{ }^{\circ} \mathrm{C}$ and kept for 30 minutes. These samples were then one end glued to a metal support using Tissue Freezing Medium (Leica, Jung, Germany) and sectioned transversely at $7 \mu \mathrm{m}$ thickness.

The cross-sections were submitted to the reaction of Nicotinamide Adenine Dinucleotide - Tretrazolium Reductase (NADH-TR), according to Pearse's technique, modified by Dubowitz and Brooke (24), which allows the analysis of the oxidative and glycolytic metabolism of the three types of muscle fibers. With this material, the quantification of the three types of fibers and the measurement of their respective cross-sectional areas were performed using the Image Pro Plus 6.0 $0^{\circledR}$ program (Media Cybernetics, Maryland, USA), with four microscopic fields (20X objective) being used for each animal.

\section{Oxidative stress analysis}

In the oxidative stress analysis, the other part of the sample from the right antymere of the diaphragm muscle was frozen in liquid nitrogen and stored in a freezer $-80^{\circ} \mathrm{C}$ for subse- quent homogenization. The samples were homogenized in 1 $\mathrm{ml}$ of Tris $\mathrm{HCl}, \mathrm{pH} 7.4$ buffer and centrifuged at 13,680 G for 10 minutes at a temperature of $4{ }^{\circ} \mathrm{C}$. The protein quantification of the samples was determined by the method of Bradford (25) using bovine serum albumin as the standard. All samples were then normalized to $1 \mathrm{mg}$ of protein $/ \mathrm{ml}$.

To evaluate the enzyme dosage, associated with the antioxidant system, the activity of Superoxide Dismutase (SOD), the activity of Catalase (CAT), the reaction of Lipoperoxidation (LPO), the activity of Glutathione S-Transferase (GST) and the activity of Glutathione Reductase (GR) were analyzed.

In the case of SOD, the method proposed by Crouch et al. (26) modified was used. The principle of this analysis consists in quantifying the complex formed between superoxide and tetrazolium blue (NBT), measured at $560 \mathrm{~nm}$ during $1 \mathrm{~h} 30 \mathrm{~min}$. An aliquot of $0.75 \mathrm{mg} / \mathrm{ml}$ of protein in $25 \%$ ethanol was prepared in a volume of $800 \mu \mathrm{L}$ and centrifuged at $13,680 \mathrm{G}\left(4^{\circ} \mathrm{C}\right)$ for 20 minutes. From the supernatant, the reaction medium was prepared in 96-well microplate, in triplicate, with a final volume of $200 \mu \mathrm{L}$, containing $0.1 \mathrm{mg}$ of protein $\times \mathrm{mL}^{-1}, 0.09 \mathrm{mM}$ of NBT, $0.015 \mathrm{mM}$ of EDTA, $34.78 \mathrm{mM}$ of hydroxylamine sulfate, $79 \mathrm{mM}$ of sodium carbonate buffer $\mathrm{pH} 10.2$ and the plate read at $22^{\circ} \mathrm{C}$, and a unit of SOD in $\mathrm{nmol} \times \mathrm{min}^{-1} \times \mathrm{mg}$ of protein ${ }^{-1}$.

The activity of CAT was accompanied by a decrease in absorbance at $240 \mathrm{~nm}$ (27), from the principle of peroxide dismutation, whose molar extinction coefficient is 40 $\mathrm{M}^{-1} \times \mathrm{cm}^{-1}$. The duplicates, in $2 \mathrm{~mL}$ of solution in a quartz bucket presented with a final concentration of $0.01 \mathrm{mg}$ of protein $\times \mathrm{mL}^{-1}$ and the reaction medium presented with final concentrations of $13.5 \mathrm{mM}$ of $\mathrm{H}_{2} \mathrm{O}_{2}, 50 \mathrm{mM}$ of TRIS$\mathrm{HCl} \mathrm{pH} 8.0$ and $0.25 \mathrm{mM}$ of EDTA. The results of the catalase enzyme activity were expressed in $\mathrm{mmol} \times \mathrm{min}^{-1}$ $\times$ mg of protein $^{-1}$.

The determination of the LPO reaction was performed to indirectly quantify the peroxides, thus reflecting the intensity of lipid peroxidation. The method of thiobarbituric acid (TBARS) (28) was performed by a comparison of absorbance with the pattern curve of Malondialdehyde (MDA), the main by-product of cellular lipid peroxidation. For sample preparation, the medium, containing an aliquot of $0.33 \mathrm{mg} / \mathrm{ml}$ of sample protein in $6.7 \%$ trichloroacetic acid in a final volume of $180 \mu \mathrm{L}$, was stirred in a vortex, left in an ice bath for 5 minutes and centrifuged for 5 minutes at $13,680 \mathrm{G}$ at $4{ }^{\circ} \mathrm{C}$. For the dosage of TBARS reactive substances, $40 \mu \mathrm{L}$ of the supernatant, as well as different concentrations of MDA, were added in a microplate, in triplicate, in the reaction medium, containing $21.42 \mathrm{mM}$ of TBA, $17.86 \mathrm{mM}$ of $\mathrm{NaOH}$ (used for solubilization of TBA), $0.73 \mathrm{M}$ of TCA, $0.032 \mathrm{mM}$ of BHT, 3\% ethanol (used for 
solubilization of BHT) in PBS. The reaction was read at 22 ${ }^{\circ} \mathrm{C}$; after 60 minutes of incubation at $60^{\circ} \mathrm{C}$ at an absorbance of $535 \mathrm{~nm}$. The results of lipid peroxidation were expressed in nmol of MDA $\times$ mg of protein ${ }^{-1}$.

The detoxification evaluation was performed by analysis of the GST enzyme activity. With the methodology of Keen et al. (29), the activity of this enzyme was measured over 5 minutes at 30-second intervals, evaluating the increase in absorbance due to the formation of a thioether at an absorbance of $340 \mathrm{~nm}$. The reaction composition is potassium phosphate buffer pH 6.5, GSH 1.5 MM, CDNB $2 \mathrm{mM}$ in 1 $\mathrm{mL}$ of ethanol. The activity of GST is expressed in $\mu$ moles of thio-ether $\times \min ^{-1} \times$ mg of protein ${ }^{-1}$.

The activity of GR was evaluated according to the technique proposed by Sies et al. (30). The reaction system was constituted of phosphate buffer $100 \mathrm{mmol} \times \mathrm{L}^{-1}(\mathrm{pH} 7.0)$, EDTA $1 \mathrm{mmol} \times \mathrm{L}^{-1}$, GSSG $0.66 \mathrm{mmol} \times \mathrm{L}^{-1}$, NADPH $0.075 \mathrm{mmol}$ $\times \mathrm{L}^{-1}$. The reaction was initiated by the addition of GSSG and monitored for 5 minutes at $340 \mathrm{~nm}$. The results were expressed in NADPH oxidized $\times \min ^{-1} \times$ mg of protein ${ }^{-1}$.

\section{Statistical analysis}

In the case of $\mathrm{NADH}$, the data were expressed as mean \pm standard deviation of the mean. For the statistical evaluation, it was used the analysis of variance (ANOVA) of two factors. When $\mathrm{F}$ is significant, the differences between the means were evaluated with a p-value corrected for Tukey. Values with $\mathrm{p}<0.05$ were considered significant. The software used for statistical analysis was GraphPad Prism version 5.0 for Windows (GraphPad Software ${ }^{\odot}$ ) (La Jolla, USA).

For the data on the activity of oxidative stress enzymes, the integrated biological response test version 2 (IBR2) was performed, which combines mathematical value with the graphic results and was applied in this study based on the evaluation of the enzymatic activities of the antioxidant system together (31). Data processing was as follows:

$$
A_{\mathrm{i}}{ }^{1 / 4} Z_{\mathrm{i}}-Z_{0} Z_{\mathrm{i}}{ }^{1 / 4} \partial Y_{\mathrm{i}}-\mu P=s Y_{\mathrm{i}}{ }^{1 / 4} \log X_{\mathrm{i}}=X_{0} \partial P
$$

$A_{i}, Z_{i}, Z_{0}, \mu, s, X_{i}$, and $X_{0}$ represented the biomarker deviation index, standardized biomarker response mean, reference biomarker data mean, general $Y_{i}$ mean, $Y_{i}$ standard deviation, individual biomarker data, and reference mean data, respectively.

For each separate factor, the parameters are reported in a star graph to represent the reference deviation of each enzyme activity investigated. Values above zero represent enzyme induction, and values below zero indicate inhibition of enzyme activity.

\section{RESULTS}

The histoenzyme study of the NADH-TR activity revealed the presence of muscle fibers of types I (small diameter and intense oxidative activity), IIA (medium diameter and moderate oxidative activity) and IIB (large diameter and low oxidative activity) in all groups studied (figure 2 A-D). The cross-sectional area of the muscle fibers showed a reduction of $21 \%$ in type IIA fibers $\left(\mathrm{F}_{1}=6.44 ; \mathrm{p}=0.02\right)$ and $31 \%$ in type IIB $\left(F_{1}=11.35 ; \mathrm{p}=0.002\right)$ in the GO and GOP groups when compared to GC and GCP (figure $3 \mathbf{B}, \mathbf{C})$. In the area of type I fibers, there was no significant difference between the groups studied and no interaction between the two factors, obesity and platform $\left(\mathrm{F}_{1,3}=0.41\right.$; $\mathrm{p}=0.53$ ) (figure $3 \mathrm{~A}$ ).

Regarding the count of the number of different types of muscle fibers, in the animals of GCP and GOP, a reduction of $21 \%$ was observed only in type IIB $\left(F_{1}=7.66 ; p=\right.$ 0.01 ), when compared to the groups GC and GO (figure 3 F). In the analyses of type I and IIA count, no significant differences were observed between the studied groups and there was also no interaction between the factors, obesity and platform (fiber type $\mathrm{I}-\mathrm{F}_{1,3}=0.75 ; \mathrm{p}=0.40$; fiber type IIA $-\mathrm{F}_{1,3}=0.04 ; \mathrm{p}=0.84$ ) (figure $3 \mathrm{D}, \mathrm{E}$ ).

The quantification of total protein in the samples in the GO and GOP groups, showed lower mean values $\left(F_{1}=6.96 ; p\right.$ $=0.01)$ than the GC and GCP groups. The analysis of the effect of WBV

training revealed no difference $\left(\mathrm{F}_{1}=0.18 ; \mathrm{p}=0.67\right)$ or interaction between the factors, obesity and WBV $\left(\mathrm{F}_{1,3}=0.17 ; \mathrm{p}\right.$ $=0.68$ ) (figure 4).

Through the IBR2 test, it was possible to verify the activity of enzymes in the oxidative system, observing that GST had greater activation in obesity and in WBV training, as well as in the association between these factors (figure 5 A-C). Additionally, the activity of CAT suffered a small reduction in obesity (figure 5 B) and the GR enzyme had its activity reduced in the association of obesity factors and vibratory platform (figure $5 \mathrm{C}$ ). On the other hand, in the evaluation of the SOD enzyme and the LPO reaction, no differences were observed in any of the factors evaluated (figure 5 A-C).

\section{DISCUSSION}

The administration of MSG in animals in their neonatal period causes lesions in the hypothalamic arched nuclei, resulting in the destruction of $70 \%$ to $90 \%$ of neural cell bodies, being one of the damages to the decrease in the secretion of growth hormone $(\mathrm{GH})$ (32), which, in turn, demonstrates to be a mediator of the metabolism of lipids, carbohydrates and proteins in the tissues of the body, as well as in the growth processes (33). Due to its relationship 


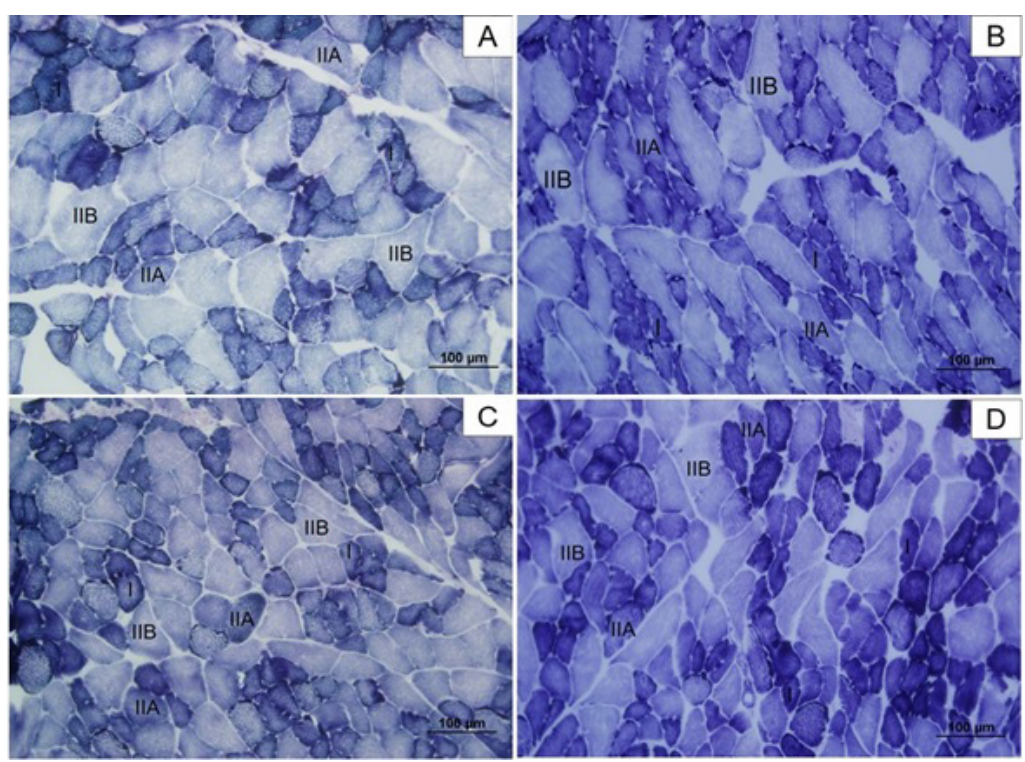

Figure 2. Photomicrographs of the diaphragm muscle of 130-day old Wistar rats. Cross-section. Type I, IIA and IIB muscle fibers. Nicotinamide Adenine Dinucleotide - Tetrazolium Reductase (NADH-TR) reaction.

A: Control Group (GC); B: Control Group exercised in WBV (GCP); C: Obese Group (GO); D: Obese group exercised in WBV (GOP).
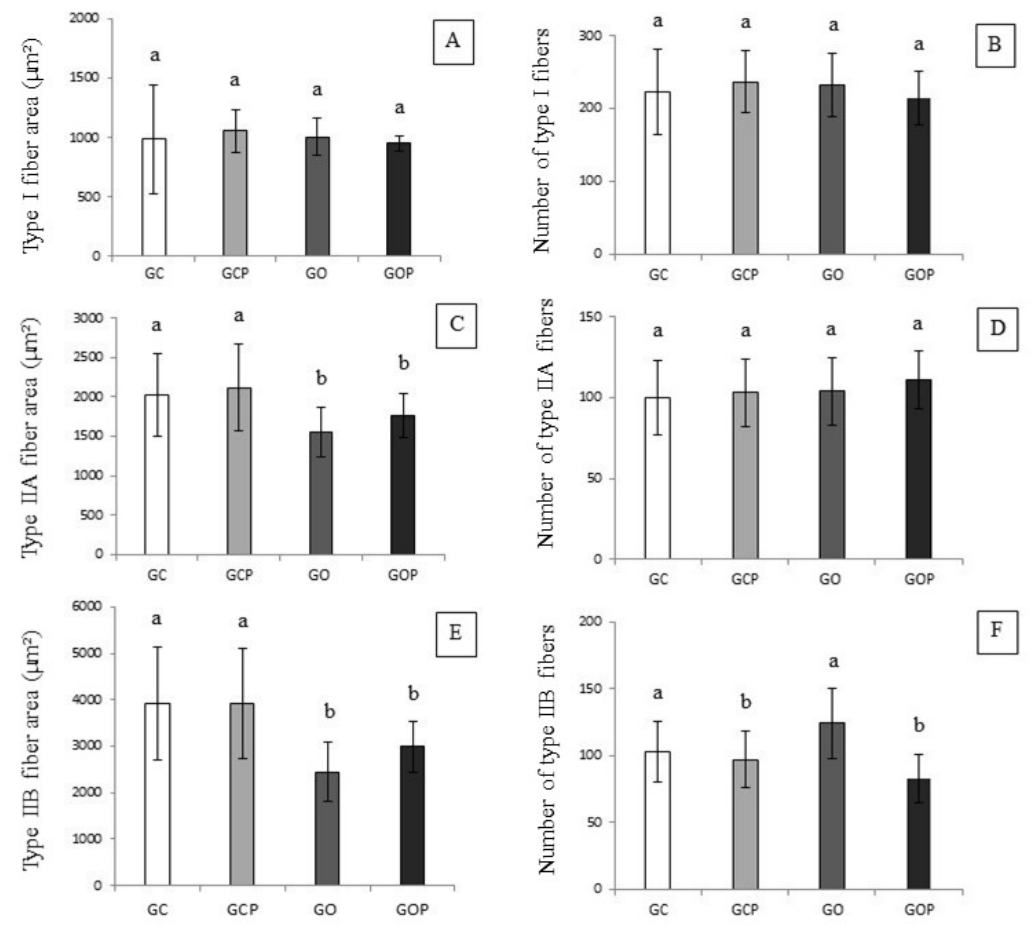

Figure 3. Morphometric analysis of the muscular fibers of the diaphragm muscle of 130-day-old Wistar rats in the control (CG), WBV trained (GCP), obese (GO) and WBV trained (GOP) groups, respectively.

A: type I fiber area; B: area of type IIA fibers; C: area of type IIB fibers; D: number of type I fibers; E: number of Type IIA fibers; F: number of type IIB fibers. Values expressed as mean and standard deviation. Different letters indicate significant differences. Two-way ANOVA variance analysis test $(p<0.05)$. 


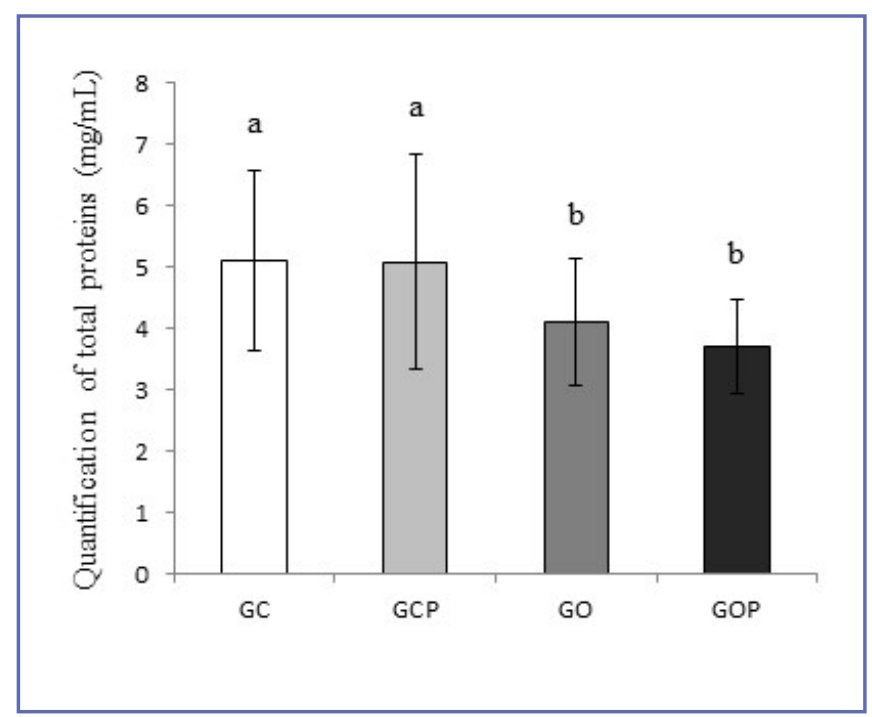

Figure 4. Analysis of the quantification of total diaphragm muscle proteins from 130-day-old Wistar rats in the control $(G C)$, WBV trained (GCP), obese (GO), and WBV trained (GOP) groups, respectively.

Values expressed as mean and standard deviation. Different letters indicate significant differences. Two-way ANOVA variance analysis test $(\mathrm{p}<0.05)$. with protein synthesis, the decrease in the concentration of this hormone leads to protein deficiency (34), corroborating with the results of this study, considering that the animals that underwent administration of MSG presented a reduction in the analysis of the quantification of total proteins of the diaphragm muscle.

In this model, through the reduction of $\mathrm{GH}$ secretion, causes protein deficiency, thus harming the development of the muscle, resulting in a reduction in the area of muscle fibers (34), an aspect observed in the present study, in which obesity, through MSG, led to a reduction in the area of type IIA fibers and the area of type IIB fibers. Additionally, the response of the muscle fibers to different stimuli is specific to the type of fiber, and more atrophy of the type II fibers is observed than of the type I fibers in conditions associated with the loss of muscle mass in disease (20), which also corroborates the findings of this study.

The muscle fibers can change their physiological and biochemical properties according to the stimuli to which they are submitted (35), and physical exercise can promote changes in muscle fibers, altering these properties, because different types of exercise can alter the amount of slow or fast fibers (36). When the number of each type of muscle fibers

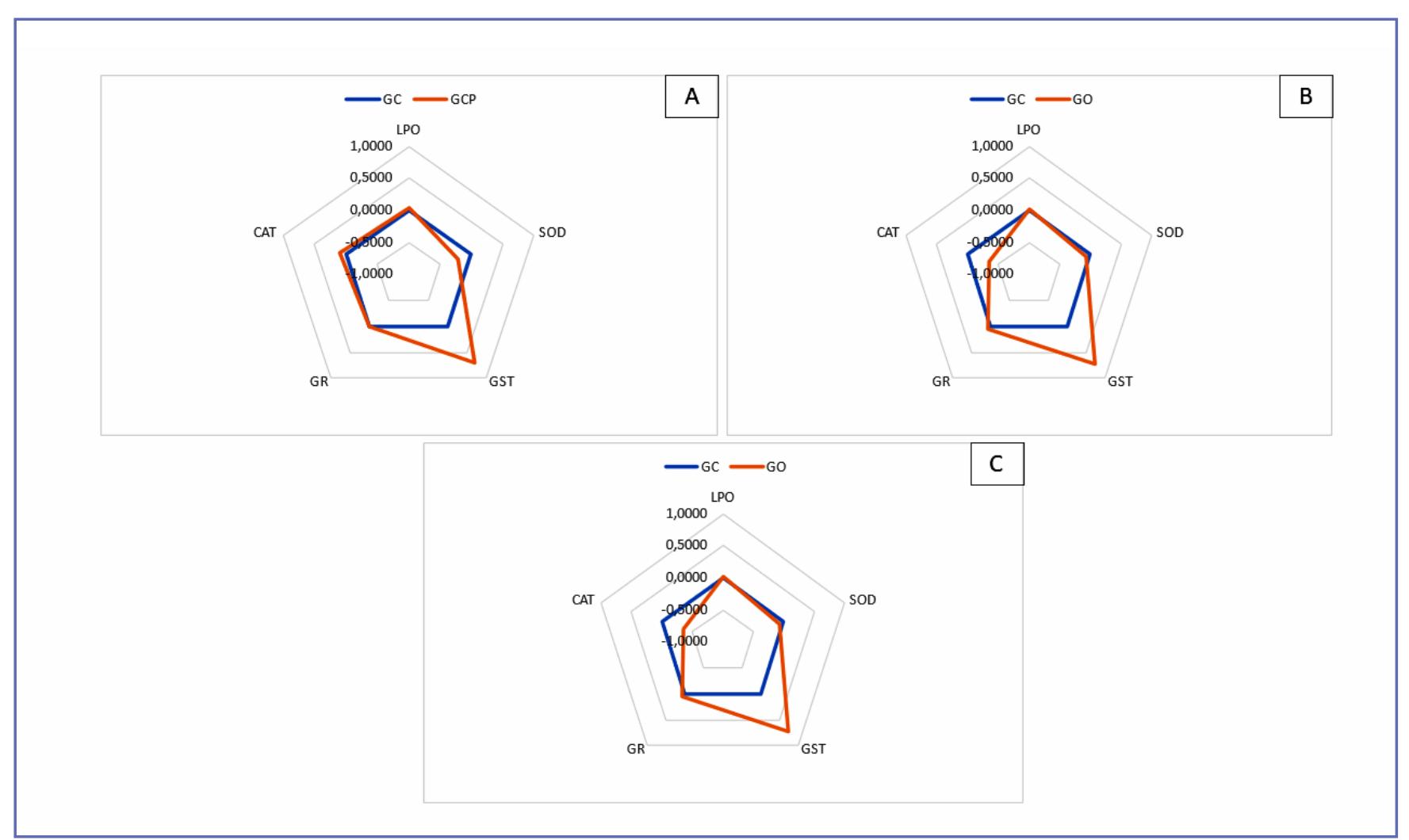

Figure 5. IBR stellar portions of the activity of enzymes present in the antioxidant defense system. A: animals trained in WBV (GCP); B: obese animals (GO); C: obese animals trained in WBV (GOP). 
was counted, a reduction was observed only in the fibers of type IIB, due to the vibratory platform. Endurance or aerobic exercises, as is the case of WBV, promote an increase in the myoglobin, in the number and size of mitochondria and also in the activity of oxidative enzymes (37), bringing an improved metabolic capacity and allowing the guarantee of activity for prolonged periods without excessive fatigue, recruiting more type I fibers $(20,38)$, which could be associated to a reduction in the number of type IIB fibers.

The data on the reduction in the amount of type IIB fibers show the adaptations of the skeletal muscle submitted to the vibratory platform exercise and reveal an important measure of its plasticity, which is the high capacity that this tissue has to undergo adaptation both structurally and functionally, considering the workload, activities and pathological conditions (38). The WBV, Park et al. (39) highlight brings positive results in the condition of a strength exercise, and the protocol used in this study was adapted from Butezloff et al. (23) in which they observed anabolic effects of WBV; however, the results obtained in this study infer possible deleterious effects on the contractile strength capacity of the diaphragm. Other studies investigating the diaphragm muscle after performing physical exercise have not revealed significant differences in the morphological parameters of percentage and cross-sectional area of muscle fibers (18). Thus, there is a need for new studies varying the time of intervention, as well as the level of intensity of exercise with WBV. It should be noted that the findings of this study are valid for the diaphragm muscle, because analyzing the lipid profile in a similar model and protocol, Andrade et al. (40) observed lipid mobilization indicating WBV as a method for metabolic rehabilitation. It was also observed by Boaretto et al. $(41,42)$ with a similar protocol, a reduction of intramuscular connective tissue, an increase in muscle fibers, and neuromuscular junction measurements, despite the absence of changes in cholinesterase concentration in the synaptic cleft of soleus.

Regarding oxidative metabolism, it has been discussed in the literature that obesity causes increased lipid peroxidation and decreased cytoprotective enzymes, resulting in progressive cellular damage generated by oxidative stress (43). In the present study, a reduction in CAT activity was observed to the detriment of obesity, corroborating the study of Antunes Neto and Paula (44) with obesity and sedentary men, in which a reduction in the activity of this enzyme was also observed. Due to the important role of CAT in the process of hydrogen peroxide breakdown, which is increased by obesity, the decrease in its activity causes, consequently, a reduction in the efficiency of the antioxidant defense system and increases the probability of growth in oxidative stress (45).
Some of the enzymes that make up the antioxidant defense system seem to work in an integrated way, and as the activity of one increases, the activity of another decreases, as is the case of glutathione reductase and catalase (46). It goes with that was observed in this study, because in obese animals, unlike Catalase, the activity of Glutathione S-Transferase presented increased and may have occurred as a protective action of cells due to its detoxifying action.

It is known that high muscle activity, promoted by physical exercises, leads to an increase in reactive oxygen species (ROS); however, regular exercises performed at moderate intensity are known to diminish a pro-inflammatory state in the body and may reinforce antioxidant defenses by adapting to oxidative stress (47). When the activity of GST in animals trained with WBV was analyzed, it was increased and may be an adaptation to combat the oxidative stress initially caused by WBV exercise.

The same result of increased GST activity was observed in the group with obese animals trained in WBV, indicating that the two factors together also influence the activity of this enzyme. However, this same group presented a reduction in the activity of GST, showing that the association of both factors also influences the activity of this enzyme. In the same way of this study, Watson et al. (48) observed the reduction of this enzyme in obese ob/ob rats, and Prada et al. (49) reported a reduction in RG in rats submitted to swim training, and no studies were found analyzing the activity of this enzyme with both associated factors. The drop in GR activity may be related to the reduction in nicotinamide adenine dinucleotide phosphate (NADPH) by pentose cycles (50), as studies show that some physical exercises, depending on their intensity, reduce the concentration of NADPH, which is one of the substrates of GR, without which the reaction catalyzed by this enzyme does not occur (51).

In the analysis of SOD activity and LPO reaction, no differences were observed in any of the factors evaluated. Studies with analysis of the effects of WBV on the activity of oxidative enzymes are very scarce in the literature. In a study that investigated the effects of training with WBV on oxidative stress in diabetic animals, Liu et al. (52) did not find differences in the activity of SOD, but the exercise was able to reduce the LPO. However, the protocol used by Liu et al. (52) was different from the present study, and the muscle under analysis as well, which may have interfered with the differing results.

\section{CONCLUSIONS}

Based on the above results, it is concluded that obesity through MSG has caused a reduction in the total proteins of the diaphragm muscle, as well as a decrease in the area 
of type IIA and IIB fibers and enzymes in the antioxidant defense system. Furthermore, it is understood that training with WBV does not seem to be a recommended resource since it has not been able to reverse the effects caused by obesity.

\section{ACKNOWLEDGMENTS}

The Araucaria Foundation by funding the research via the Basic and Applied Research Notice.

\section{CONFLICT OF INTERESTS}

The authors declare that they have no conflict of interests.

\section{REFERENCES}

1. James WPT. Obesity: A global public health challenge. Clin Chem 2018;64(1):24-9.

2. Aune D, Sen A, Prasad M, et al. BMI and all cause mortality: systematic review and non-linear dose-response meta-analysis of 230 cohort studies with 3.74 million deaths among 30.3 million participants. BMJ 2016;353:i2156.

3. Kolotkin RL, Andersen JR. A systematic review of reviews: exploring the relationship between obesity, weight loss and health-related quality of life. Clin Obes 2017;7(5):273-89.

4. Ruegsegger GN, Booth FW. Health Benefits of Exercise. Cold Spring Harb Perspect Med 2018;8(7):a029694.

5. Metsios GS, Kitas GD. Physical activity, exercise and rheumatoid arthritis: Effectiveness, mechanisms and implementation. Best Pract Res Clin Rheumatol 2018;32(5):669-82.

6. Denison HJ, Cooper C, Sayer AA, Robinson SM. Prevention and optimal management of sarcopenia: A review of combined exercise and nutrition interventions to improve muscle outcomes in older people. Clin Interv Aging 2015;10:859-69.

7. Figueroa A, Gil R, Wong A, et al. Whole-body vibration training reduces arterial stiffness, blood pressure and sympathovagal balance in young overweight/obese women. Hypertens Res 2012;35(6):667-72.

8. Xu J, Lombardi G, Jiao W, Banfi G. Effects of exercise on bone status in female subjects, from young girls to postmenopausal women: an overview of systematic reviews and meta-analyses. Sport Med 2016;46(8):1165-82.

9. Goebel R, Haddad M, Kleinöder H, Yue Z, Heinen T, Mester $J$. Does combined strength training and local vibration improve isometric maximum force? A pilot study. Muscles Ligaments Tendons J 2017;7(1):186-91.

10. Mohd Mukhtar A, Abid AK, Mohd F. Effects of different vibration therapy protocols on neuromuscular performance. Muscles Ligaments Tendons J 2021;11(1):161-77.

11. Saxena A, St. Louis M, Fournier M. Vibration and pressure wave therapy for calf strains: A proposed treatment. Muscles Ligaments Tendons J 2013;3(2):60-2.
12. Cakar HI, Cidem M, Sebik O, et al. Whole-body vibration-induced muscular reflex: Is it a stretch-induced reflex? J Phys Ther Sci 2015;27(7):2279-84.

13. Bertucci WM, Arfaoui A, Duc S, Letellier T, Abderrahim. Effect of whole body vibration in energy expenditure and perceived exertion during intense squat exercise. Acta Bioeng Biomech 2015;17(1):87-93.

14. Zago M, Capodaglio P, Ferrario C, Tarabini M, Galli M. Whole-body vibration training in obese subjects: A systematic review. PLoS One 2018;13(9):e0202866.

15. Alavinia SM, Omidvar M, Craven BC. Does whole body vibration therapy assist in reducing fat mass or treating obesity in healthy overweight and obese adults? A systematic review and meta-analyses. Disabil Rehabil 2021;43(14):1935-47.

16. Castello V, Simões RP, Bassi D, Mendes RG, Borghi-Silva A. Força muscular respiratória é marcantemente reduzida em mulheres obesas mórbidas / Respiratory muscle strength is markedly reduced in morbid obese women. Arq méd ABC 2007;32(2):74-7.

17. Maikala RV, King S, Bhambhani YN. Cerebral oxygenation and blood volume responses to seated whole-body vibration. Eur J Appl Physiol 2005;95(5-6):447-53.

18. Reid WD, Shanks J, Samrai B. Regional and fiber-type percentages and sizes in the hamster diaphragm after swim training. Phys Ther 1997;77(2):178-86.

19. Luciano E, Rostom de Mello MA. Efeitos do exercício físico crônico sobre as proteínas no diafragma de ratos diabéticos. Motriz J Phys Educ UNESP 1999;5(2):146-51.

20. Frontera WR, Ochala J. Skeletal muscle: A brief review of structure and function. Calcif Tissue Int 2015;96(3):183-95.

21. Padulo J, Oliva F, Frizziero A, Maffulli N. Basic principles and recommendations in clinical and field science research: 2018 update. Muscles Ligaments Tendons J 2018;8(3):305-7.

22. Olney JW. Brain lesions, obesity, and other disturbances in mice treated with monosodium glutamate. Science 1969;164(3880):719-21.

23. Butezloff MM, Zamarioli A, Leoni GB, Sousa-Neto MD, Volpon JB. Whole-body vibration improves fracture healing and bone quality in rats with ovariectomy-induced osteoporosis. Acta Cirúrgica Bras 2015;30(11):727-35.

24. Dubowitz V, Brooke M. Muscle biopsy: a modern approach. 1st ed. London: Saunders; 1973.

25. Bradford MM. A rapid and sensitive method for the quantitation of microgram quantities of protein utilizing the principle of protein-dye binding. Anal Biochem 1976;72(1-2):248-54 .

26. Crouch RK, Gandy SE, Kimsey G, Galbraith RA, Galbraith GM, Buse MG. The inhibition of islet superoxide dismutase by diabetogenic drugs. Diabetes 1981;30(3):235-41.

27. Aebi H. Catalase in vitro. Methods Enzymol 1984;105:121-6.

28. Buege JA, Aust SD. Microsomal lipid peroxidation. Methods Enzymol 1978;52:302-10.

29. Keen H, Habig WH, Jakoby B. Mechanism for the several activities of the glutathione S-transferases. J Biol Chem 1976;251(20):6183-8.

30. Sies H, Koch OR, Martino E, Boberis A. Increased biliary glutathione disulfide release in chronically ethanol-treated rats. Febs Lett 1979;103(2):287-90. 
31. Sanchez W, Burgeot T, Porcher JM. A novel "Integrated Biomarker Response" calculation based on reference deviation concept. Environ Sci Pollut Res 2013;20(5):2721-5.

32. Maiter D, Underwood LE, Martin JB, Koenig JI. Neonatal treatment with monosodium glutamate: effects of prolonged growth hormone $(\mathrm{GH})$-releasing hormone deficiency on pulsatile GH secretion and growth in female rats. Endocrinology 2015;128(2):1100-6.

33. Thomas GA, Kraemer WJ, Comstock BA, Dunn-Lewis C, Maresh CM, Volek JS. Obesity, growth hormone and exercise. Sport Med 2013;43(9):839-49.

34. Clanton TL, Klawitter PF. Physiological and genomic consequences of intermittent hypoxia invited review: adaptive responses of skeletal muscle to intermittent hypoxia: the known and unknown. J Appl Physiol 2001;90(6):2476-87.

35. DeNies MS, Johnson J, Maliphol AB, et al. Diet-induced obesity alters skeletal muscle fiber types of male but not female mice. Physiol Rep 2014;2(1):e00204.

36. Osório Alves J, Matta Pereira L, Cabral Coutinho do Rêgo Monteiro I, et al. Strenuous acute exercise induces slow and fast twitch-dependent NADPH oxidase expression in rat skeletal muscle. Antioxidants 2020;9(1):57.

37. Rizo-Roca D, Ríos-Kristjánsson JG, Núñez-Espinosa C, et al. Modulation of mitochondrial biomarkers by intermittent hypobaric hypoxia and aerobic exercise after eccentric exercise in trained rats. Appl Physiol Nutr Metab 2017;42(7):683-93.

38. Qaisar R, Bhaskaran S, Van Remmen H. Muscle fiber type diversification during exercise and regeneration. Free Radic Biol Med 2016;98:56-67.

39. Park S-Y, Son W-M, Kwon O-S. Effects of whole body vibration training on body composition, skeletal muscle strength, and cardiovascular health. J Exerc Rehabil 2015;11(6):289-95.

40. de Andrade BZ, Zazula MF, Bittencourt Guimarães AT, et al. Whole-body vibration promotes lipid mobilization in hypothalamic obesity rat. Tissue Cell 2021;68:101456.

41. Boaretto ML, de Andrade BZ, Hoff Nunes Maciel JI, et al. Alterations in neuromuscular junctions and oxidative stress of the soleus muscle of obese Wistar rats caused by vibratory platform training. J Musculoskelet Neuronal Interact Orig 2020;1-9.

42. Boaretto ML, de Andrade BZ, Maciel JIHN, et al. Effects of vibratory platform training on the histomorphometric parame- ters of the soleus muscle in obese Wistar rats. Sport Sci Health 2020;16:501-10.

43. França BK, Melo Alves MR, Silveira Souto FM, et al. Peroxidação lipídica e obesidade: Métodos para aferição do estresse oxidativo em obesos. GE J Port Gastrenterologia 2013;20(5):199-206.

44. Antunes Neto JMMF, Paula LB. Índices de estresse oxidativo em sujeitos com diferentes níveis de composição corporal e aderência a prática de atividade física. Brazilian J Biomotricity 2011;5(2):117-31.

45. Bausenwein J, Serke H, Eberle K, et al. Elevated levels of oxidized low-density lipoprotein and of catalase activity in follicular fluid of obese women. Mol Hum Reprod 2010;16(2):117-24.

46. Zoppi CC, Antunes-Neto J, Catanho FO, Goulart LF, Moura NM, Macedo D V. Alterações em biomarcadores de estresse oxidativo, defesa antioxidante e lesão muscular em jogadores de futebol durante uma temporada competitiva. Rev Paul Educ Física 2003;17(2):119-30.

47. Steinbacher P, Eckl P. Impact of Oxidative Stress on Exercising Skeletal Muscle. Biomolecules 2015;5(2):356-77.

48. Watson AM, Poloyac SM, Howard G, Blouin RA. Effect of leptin on cytochrome P-450, conjugation, and antioxidant enzymes in the ob/ob mouse. Drug Metab Dispos 1999;27(6):695-700.

49. Prada FJA, Voltarelli FA, Oliveira CAM de, Gobatto CA, Macedo DV, Mello MAR de. Condicionamento aeróbio e estresse oxidativo em ratos treinados por natação em intensidade equivalente ao limiar anaeróbio / Aerobic condition and oxidative stress in rats swim-trained at the anaerobic threshold intensity. Rev Bras Ciência e Mov 2004;12(2):29-34.

50. Rover Júnior L, Höehr NF, Vellasco AP, Kubota LT. Sistema antioxidante envolvendo o ciclo metabólico da glutationa associado a métodos eletroanalíticos na avaliação do estresse oxidativo. Quim Nova 2001;24(1):112-9.

51. Tauler P, Gimeno I, Aguiló A, Guix MP, Pons A. Regulation of erythrocyte antioxidant enzyme activities in athletes during competition and short-term recovery. Pflügers Arch - Eur J Physiol 1999;438:782-7.

52. Liu Y, Zhai M, Guo F, et al. Whole body vibration improves insulin resistance in $\mathrm{db} / \mathrm{db}$ mice: amelioration of lipid accumulation and oxidative stress. Appl Biochem Biotechnol 2016;179(5):819-29. 